\title{
DGA Method-Based ANFIS Expert System for Diagnosing Faults and Assessing Quality of Power Transformer Insulation Oil
}

\author{
Mohd Muhridza Bin Yaacob', Ahmed Raisan Hussein ${ }^{1} \&$ Mohd Fauzi Bin Othman ${ }^{2}$ \\ ${ }^{1}$ Institute of High Voltage and High Current, Faculty of Electrical Engineering, Universiti Teknologi Malaysia, \\ Malaysia \\ ${ }^{2}$ Centre for Artificial Intelligence and Robotic, Faculty of Electrical Engineering, Universiti Teknologi Malaysia, \\ Malaysia
}

Correspondence: Ahmed Raisan Hussein, Institute of High Voltage and High Current, Faculty of Electrical Engineering, Universiti Teknologi Malaysia, 81310, UTM Skudai, Johor, Malaysia. Tel: 60-107-553-5695. Fax: 6107-557-8150. E-mail: ahmad_rissan@yahoo.com

Received: April 28, 2015

Accepted: August 28, 2015

Online Published: December 21, 2015

doi:10.5539/mas.v10n1p13

URL: http://dx.doi.org/10.5539/mas.v10n1p13

\begin{abstract}
Accurate fault diagnostics and assessment of electrical power transformer insulation oil for lifelong endurance are the key issues addressed in this research. The durability of a transformer is significantly determined by the quality of its insulation oil, which deteriorates over time due to temperature fluctuations and moisture content. Protecting transformers from potential failure through early and precise diagnosis of faults and through efficient assessment of oil quality during the actual conduct of the operation can avoid sizeable economic losses. The ANFIS Expert System that uses intelligent software plays an important role in this regard. The dissolved gas analysis (DGA) in oil is a reliable method for diagnosing faults and assessing insulation oil quality in transformers. The safeguarding teams of transformer power stations often suffer from the occurrence of sudden faults, which result in severe damages and heavy monetary loss. The oil in transformers must be appropriately treated to circumvent such failures. In this research, an ANFIS Expert System was used to diagnose faults and to assess the status and quality of insulation oil in power transformers. A suitable treatment was identified using the Rogers ratio method depending on the DGA in oil. The graphical user interface from the MATLAB environment was used and proven effective for fault diagnosis and oil quality evaluation. The training algorithm is capable of assessing oil quality according to the specifications of the IEEE standard C57-104 and the IEC standard 60599.
\end{abstract}

Keywords: expert system, IEC method, insulation oil, fault diagnosis, power transformer, Rogers method

\section{Introduction}

Electricity has become an important part of human life. At present, it is difficult to imagine life without electricity. Electricity has become a basic need for people, agriculture, and the industry; hence, it has a strong impact on the economy of any country. A suitable method for accurate fault diagnostics and assessment of the oil quality of electrical power transformer is needed to ensure long-term protection. The longevity of a transformer is determined by its insulating quality. Generally, insulation deteriorates over time due to fluctuations in temperature, moisture, oxygen, and other environmental factors. Diagnosis of faults and assessment of oil quality are important steps in protecting transformers from operational failures. Power transformers are exceptionally expensive and damage to the insulation system often causes high economic loss(Sun et al., 2010) . In the past, several methods were adopted for the diagnosis of faults and for assessing oil quality in transformers; different standards with approved specifications were developed, including the IEEE standard C57-104 and the IEC standard 60599 (Committee et al., 2009; Rogers, 1978). Most of the assessment and diagnosis methods were based on dissolved gas analysis (DGA). Despite many efforts, efficient and precise methods for determining the nature of faults and the subsequent rectification mechanisms that can attain superior performance.

Electrical transformer oils are known to possess a dual function: insulation and cooling. The superior insulation and cooling capacity of electrical transformer oils that enables the transformer to withstand severely elevated changes in temperature over an extended period of operation protects transformers from faults. However, high electrical pressure, temperature, and harsh environmental conditions produce hydrocarbons (gases) in transformer oils, which affect its function negatively. Therefore, preventive maintenance schedules for fault 
diagnosis and quality assessment of transformer oils are obligatory(Shirkhodaie et al., 1998).

Several methods have been developed for fault diagnosis. Methods for assessing oil quality, on the other hand, is another topic. The various types of incipient faults that occur in transformers are arcing, corona discharge, low energy sparking, severe overloading, and overheating. These are some of the mechanisms that can result in chemical decomposition of the insulating material, as well as in the formation of various combustible and non-combustible gases, such as methane $\left(\mathrm{CH}_{4}\right)$, ethane $\left(\mathrm{C}_{2} \mathrm{H}_{6}\right)$, ethylene $\left(\mathrm{C}_{2} \mathrm{H}_{4}\right)$, acetylene $\left(\mathrm{C}_{2} \mathrm{H}_{2}\right)$, and hydrogen $\left(\mathrm{H}_{2}\right)$. Decomposition generates gaseous products that can be dissolved in mineral oil(Silva et al., 2000). DGA, a popular conventional method for assessing the condition of an oil-filled transformer, involves analysis of the gases dissolved in the insulating medium. This method is widely used by electric companies and has received worldwide recognition because of its reliability in the detection of incipient faults in power transformers. However, DGA method provides results based on empirical evidence; hence, the approach does not offer a mathematical description. In response, several soft computing techniques based on DGA have been proposed to enhance the diagnosis capabilities and effectiveness of the existing DGA method(Satyanarayana et al., 2008).

\section{Dissolved Gas Analysisd}

The DGA in oil involves taking a sample of transformer oil to determine the concentration and ratio of gases in the sample. These gases are formed by the following factors: high temperatures, partial discharge, arcing, and corona. These factors lead to the decomposition of the oil hydrocarbons (compounds of carbon and hydrogen). These gases are classified into two types: combustible gas and non-combustible gas. Combustible gases include carbon monoxide $(\mathrm{CO})$, hydrogen $\left(\mathrm{H}_{2}\right)$, methane $\left(\mathrm{CH}_{4}\right)$, acetylene $\left(\mathrm{C}_{2} \mathrm{H}_{2}\right)$, ethylene $\left(\mathrm{C}_{2} \mathrm{H}_{4}\right)$, and ethane $\left(\mathrm{C}_{2} \mathrm{H}_{6}\right)$. Noncombustible gases include, oxygen $\left(\mathrm{O}_{2}\right)$, nitrogen $\left(\mathrm{N}_{2}\right)$, and carbon dioxide $\left(\mathrm{CO}_{2}\right)$. When these gases are present in the oil sample, these exist at different rates and are generated with different rates. Some of the gases vary in ratio from time to time, depending on the changes in temperature and the age of the transformers(Anon n.d, 2000) .

\subsection{Rogers Ratio Method}

In this method, four ratios are accounted for: $\mathrm{CH}_{4} / \mathrm{H}_{2}, \mathrm{C}_{2} \mathrm{H}_{2} / \mathrm{CH}_{4}, \mathrm{C}_{2} \mathrm{H}_{4} / \mathrm{C}_{2} \mathrm{H}_{6}$, and $\mathrm{C}_{2} \mathrm{H}_{2} / \mathrm{C}_{2} \mathrm{H}_{4}$. Diagnosis of faults is accomplished via a simple coding scheme based on ranges presented in Table 1. Ratios are coded to identify 12 types of faults in transformers to identify the types of faults as shown Table 2(Muhamad et al., 2007).

Table 1. Rogers ratio code

\begin{tabular}{cll}
\hline & $<0.1$ & 5 \\
$\mathrm{CH}_{4} / \mathrm{H}_{2}$ & $0.1-1$ & 0 \\
& $1--3$ & 1 \\
& $>3$ & 2 \\
\hline $\mathrm{C}_{2} \mathrm{H}_{6} / \mathrm{CH}_{4}$ & $<1$ & 0 \\
& $>1$ & 1 \\
\hline & $<1$ & 0 \\
$\mathrm{C}_{2} \mathrm{H}_{4} / \mathrm{C}_{2} \mathrm{H}_{6}$ & $1-3$ & 1 \\
& $>3$ & 2 \\
\hline & $<0.5$ & 0 \\
$\mathrm{C}_{2} \mathrm{H}_{2} / \mathrm{C}_{2} \mathrm{H}_{4}$ & $0.5-3$ & 1 \\
& $>3$ & 2 \\
\hline & &
\end{tabular}

Table 2. Fault types according to rogers ratio method

\begin{tabular}{cccccl}
\hline No. & $\mathrm{CH}_{4} / \mathrm{H}_{2}$ & $\mathrm{C}_{2} \mathrm{H}_{6} / \mathrm{CH}_{4}$ & $\mathrm{C}_{2} \mathrm{H}_{4} / \mathrm{C}_{2} \mathrm{H}_{6}$ & $\mathrm{C}_{2} \mathrm{H}_{2} / \mathrm{C}_{2} \mathrm{H}_{4}$ & Fault type \\
\hline 1 & 0 & 0 & 0 & 0 & No fault \\
2 & $1-2$ & 0 & 0 & 0 & $<150{ }^{\circ} \mathrm{C}$ thermal fault \\
3 & $1-2$ & 1 & 0 & 0 & $150-200^{\circ} \mathrm{C}$ thermal fault \\
4 & 0 & 1 & 0 & 0 & $200-300^{\circ} \mathrm{C}$ thermal fault \\
5 & 0 & 0 & 1 & 0 & General conductor overheating \\
6 & 1 & 0 & 1 & 0 & Winding circulating currents \\
7 & 1 & 0 & 2 & 0 & Core and tank circulating currents overheated joints \\
8 & 5 & 0 & 0 & 0 & Partial discharge \\
9 & 5 & 0 & 0 & $1-2$ & Partial discharge with tracking \\
\hline
\end{tabular}




\begin{tabular}{cccccl}
\hline 10 & 0 & 0 & 0 & 1 & Flashover without power follow-through \\
11 & 0 & 0 & $1-2$ & $1-2$ & Arc with power follow- through \\
12 & 0 & 0 & 2 & 2 & Continuous sparking to floating potential \\
\hline
\end{tabular}

\subsection{IEC Ratio Method}

In the IEC ratio method, the objective is to create three ratios $\left(\mathrm{C}_{2} \mathrm{H}_{2} / \mathrm{C}_{2} \mathrm{H}_{4}, \mathrm{CH}_{4} / \mathrm{H}_{2}\right.$, and $\left.\mathrm{C}_{2} \mathrm{H}_{4} / \mathrm{C}_{2} \mathrm{H}_{6}\right)$, to allow comparison between the result of this method and that of the Rogers method. In this method, the ratio, $\mathrm{C}_{2} \mathrm{H}_{6} / \mathrm{CH}_{4}$, was excluded because it indicates a limited temperature range of decomposition. The coding of the three gas ratios are presented in Table 3. The nine fault types are shown in Table 4(Sarma \& Kalyani, 2004).

Table 3. Iec code ratio

\begin{tabular}{cccc}
\hline $\begin{array}{c}\text { IEC } \\
\text { Ratio of characteristic gases }\end{array}$ & $\begin{array}{c}\underline{\mathrm{C}}_{2} \underline{\mathrm{H}}_{2} \\
\mathrm{C}_{2} \mathrm{H}_{4}\end{array}$ & $\begin{array}{c}\mathrm{CH}_{4} \\
\mathrm{H}_{2}\end{array}$ & $\begin{array}{c}\underline{\mathrm{C}}_{2} \underline{\mathrm{H}}_{4} \\
\mathrm{C}_{2} \mathrm{H}_{6}\end{array}$ \\
\hline$<0.1$ & 0 & 1 & 0 \\
$0.1-1$ & 1 & 0 & 0 \\
$1-3$ & 1 & 2 & 1 \\
$>3$ & 2 & 2 & 2 \\
\hline
\end{tabular}

Table 4. Fault types according to the iec ratio method

\begin{tabular}{|c|c|c|c|c|}
\hline Case No. & $\begin{array}{l}\underline{\mathrm{C}}_{2} \underline{\mathrm{H}}_{2} \\
\mathrm{C}_{2} \mathrm{H}_{4}\end{array}$ & $\begin{array}{r}\underline{\mathrm{CH}}_{4} \\
\mathrm{H}_{2}\end{array}$ & $\begin{array}{l}\underline{\mathrm{C}}_{2} \underline{H}_{4} \\
\mathrm{C}_{2} \mathrm{H}_{6}\end{array}$ & Characteristic fault \\
\hline 0 & 0 & 0 & 0 & No fault \\
\hline 1 & $\begin{array}{l}0 \\
\text { But not } \\
\text { significant }\end{array}$ & 1 & 0 & Partial discharges of low energy density \\
\hline 2 & 1 & 1 & 0 & Partial discharges of low energy density \\
\hline 3 & $1-2$ & 0 & $1-2$ & Discharges of low energy \\
\hline 4 & 1 & 0 & 2 & Discharges of High Energy \\
\hline 5 & 0 & 0 & 1 & Thermal fault of low Temperature $<150^{\circ} \mathrm{C}$ \\
\hline 6 & 0 & 2 & 0 & $\begin{array}{l}\text { Thermal fault of low Temperature } \\
<1500^{\circ} \mathrm{C}-300^{\circ} \mathrm{C}\end{array}$ \\
\hline 7 & 0 & 2 & 1 & $\begin{array}{l}\text { Thermal fault of medium temperature range } \\
300^{\circ} \mathrm{C}-700^{\circ} \mathrm{C}\end{array}$ \\
\hline 8 & 0 & 2 & 2 & Thermal fault of high temperature $>700^{\circ} \mathrm{C}$ \\
\hline
\end{tabular}

\section{ANFIS Expert System}

Expert systems fall under the artificial intelligence category of computer applications. Designing an expert system needs a knowledge engineer - an individual who studies how human experts make decisions and translates the findings into rules that a computer can understand. ANFIS, derived from the term adaptive network-based fuzzy inference engine, was first proposed. This system was designed to allow if-then rules and membership functions to be constructed based on the historical data of established metrics. The system was also designed with an adaptive nature for automatic tuning purposes (Foong et al., 2009). 


\subsection{Design ANFIS Expert System}

The expert system was designed according to the flowchart shown fig 1 . The design provides an interface where the user can input gas values derived from the analysis of samples of transformer oil through dissolved gas ratios. Subsequently, the user can choose the method to be used in the analysis process. The system then uses ANFIS to process the data.

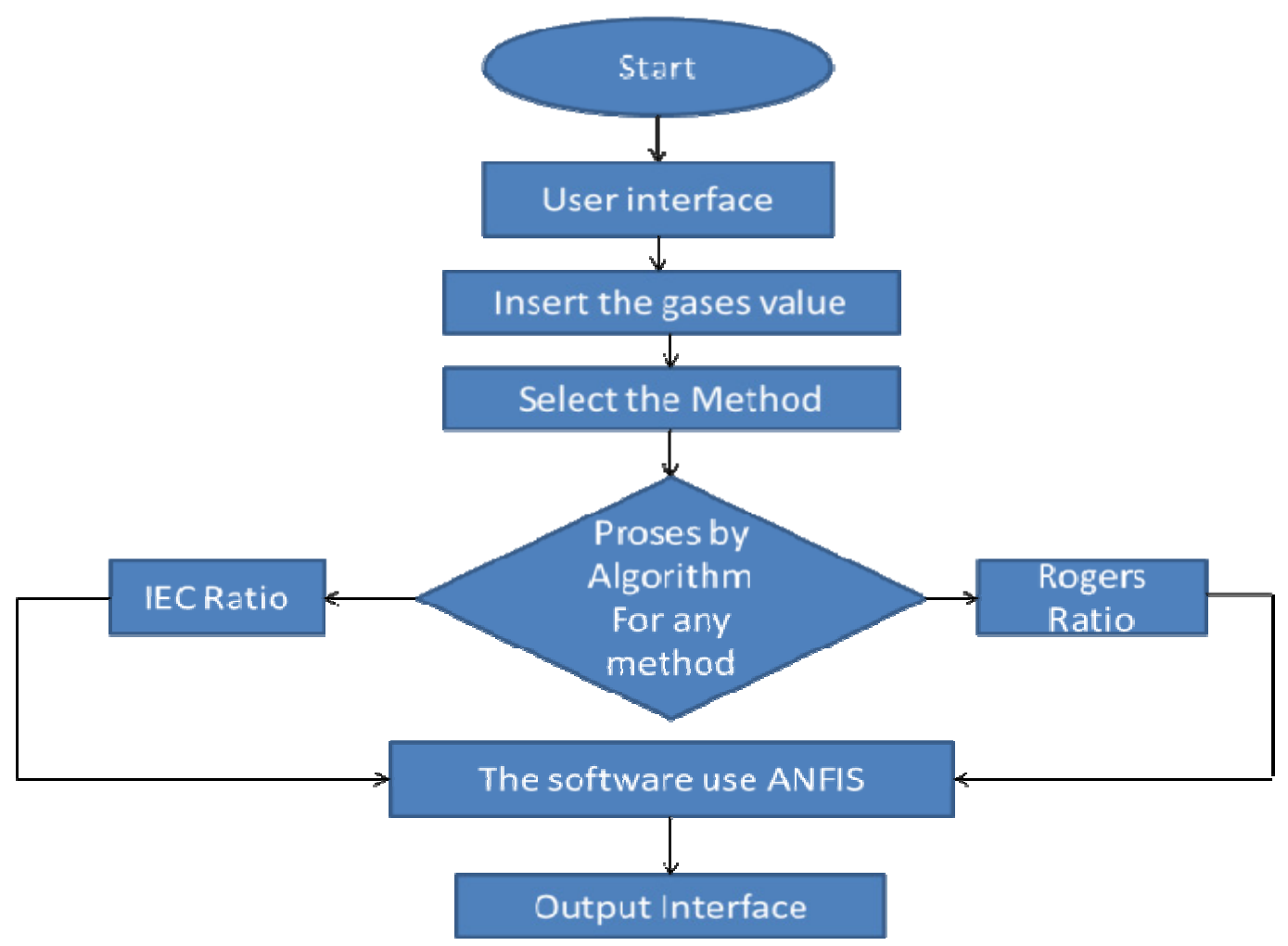

Figure 1. Flowchart for ANFIS Expert System Design

\subsection{Design of the ANFIS Expert System Interface}

The user interface of the ANFIS expert system was designed using GUI access provided in the MATLAB environment. As depicted in Figure 2, the user input interface allows the following items to be entered: gas values, analysis methods (Rogers ratio method or IEC ratio method), gas ratios, fault type diagnosis, and assessment of the quality of insulating oil (Gao et al., 1998). 


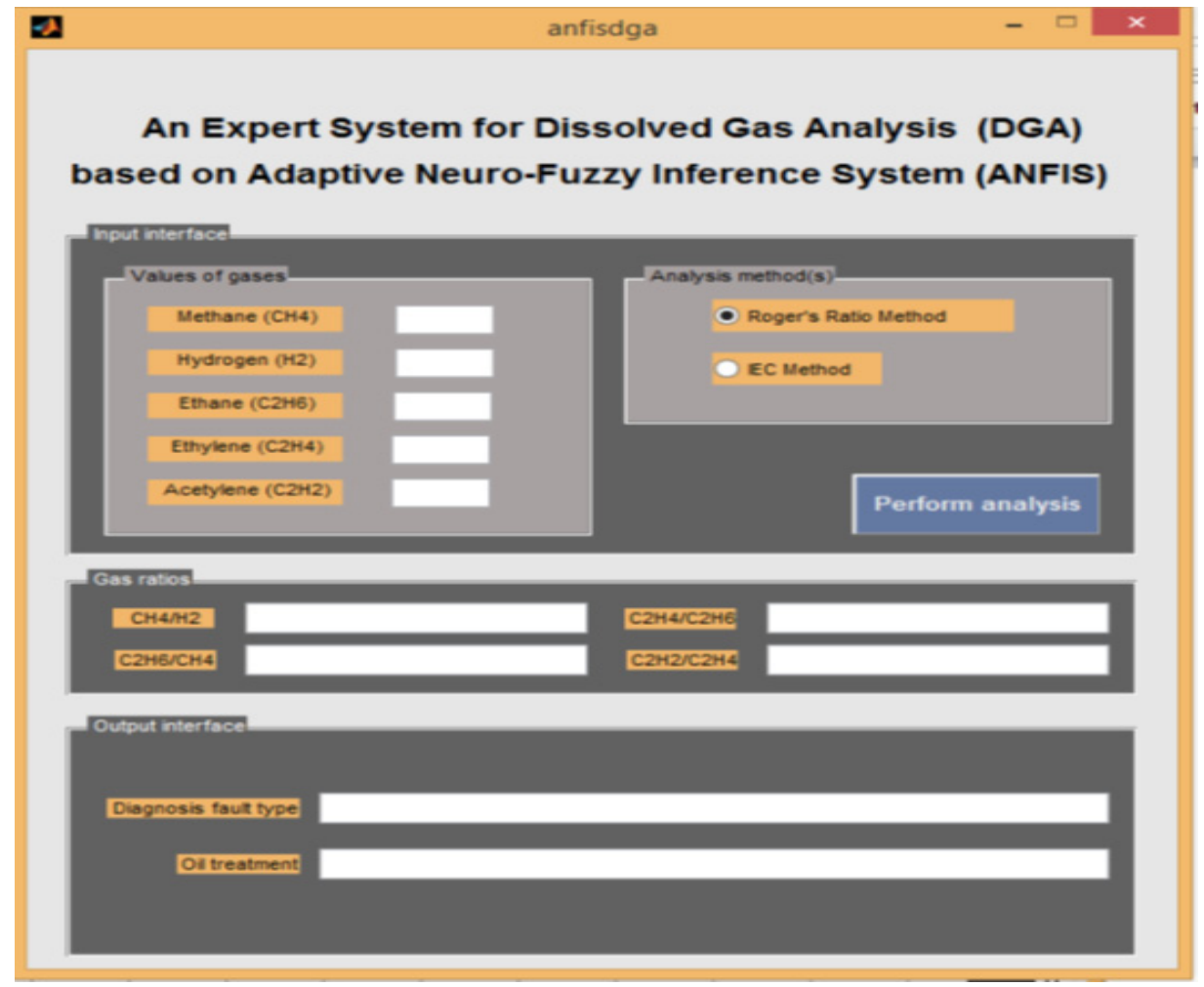

Figure 2. Interface of the ANFIS Expert System

\subsection{ANFIS Models}

Fuzzy inference is the process of formulating the mapping from a given input to an output using fuzzy logic. The mapping is then used as a basis for making decisions. The process of fuzzy inference involves membership functions, logical operations, and if-then rules. Fuzzy Inference System (FIS) 5 maps the input characteristics to input membership functions in rules to output membership function to single-value output. The shape of membership functions depends on the parameters. ANFIS chooses the parameters of membership functions automatically during the learning phase to match the system's output with the target output. Hence, ANFIS can be used for modeling a system where input/output data are available for modeling but no predetermined model for the system exists. Parameters of membership functions could be defined to fit the membership functions of the input/output data, as depicted in Figure 3.

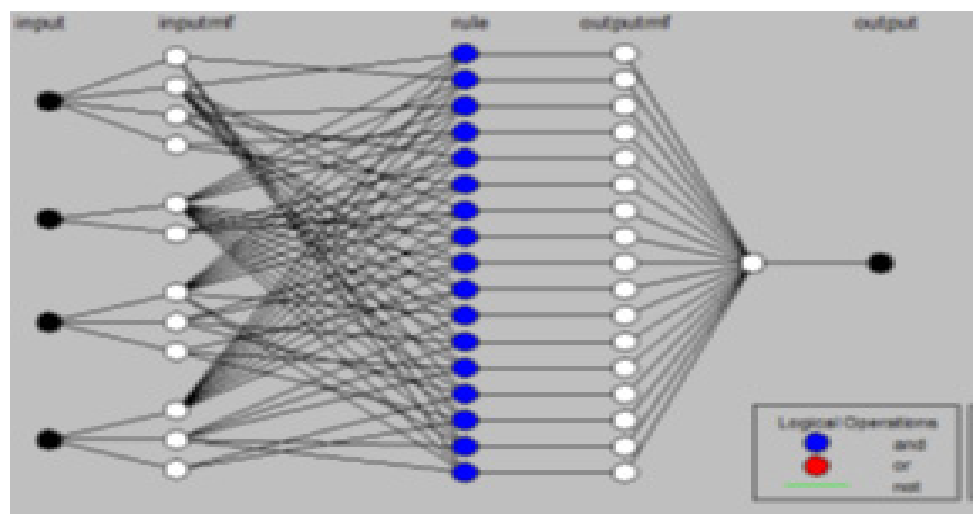

Figure 3. ANFIS structure

ANFIS was tested using 180 training samples. In ANFIS, the diagnosis of each crisp value of gas ratio is represented by a trapezoidal membership function (Figure 4). The set of fuzzy rules relates the input variables to the output. The fuzzy inference engine in the ANFIS network uses if-then rule-based system, given by IF 
antecedent and Then Consequent, a fuzzy rule set of 12 rules for Rogers Ratio Method based ANFIS and a fuzzy rule set of 9 rules for IEC Ratio Method based ANFIS.
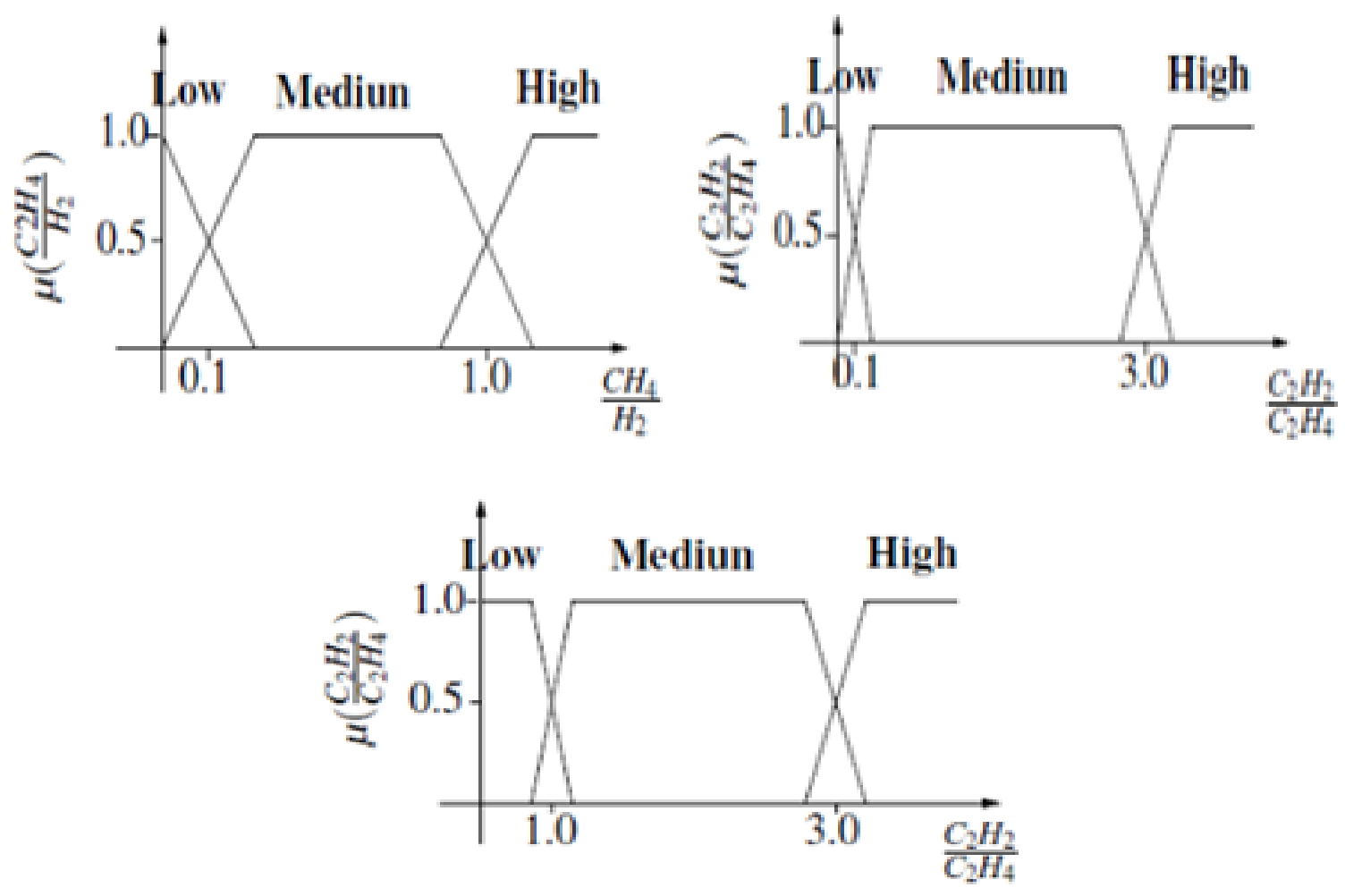

Figure 4. Input membership functions for ANFIS

For the assessment of the quality of transformer oil, the input variable TCG uses a different set of terms (Low, Moderate, High, V. High, and Severe). The input membership functions and the different set of terms are shown in Figure 5. Only one output variable is assigned to transformer oil quality. This is called oil degradation index (ODI). ODI value is computed for each input.The input membership functions are designed to give a constant output over a substantial range. The membership of each input variable varies over a definite range, uniformly on both sides (trapezoidal). This is an extremely useful property for monitoring normal changes due to operation and ageing. Another significant feature of the ODI value is its correlation with the specific reconditioning procedures for transformer oil. The output membership functions are shown in Figure 6. MF 1= Good Oil, MF 2 $=$ Single Filtering and Degassing, MF $3=$ Double Filtering and Degassing, MF $4=$ Reclamation and MF $5=$ Don't Use the Oil.

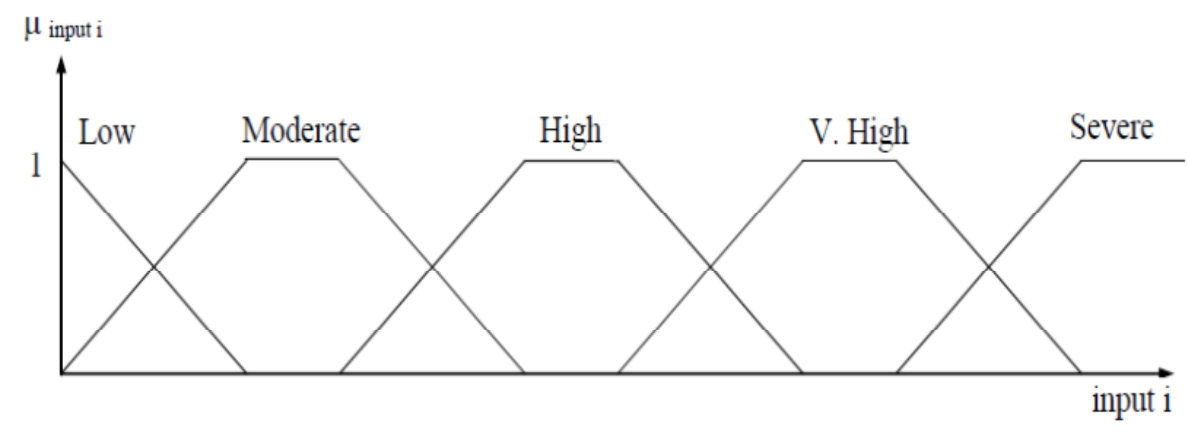

Figure 5. Input membership function used in oil reconditioning 


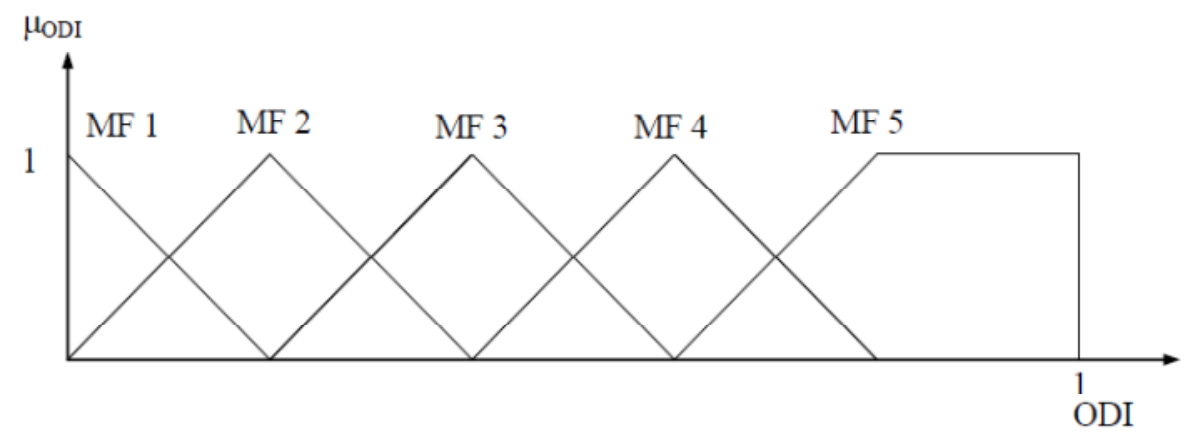

Figure 6. Output membership function

The ANFIS responses obtained from the tested set are shown in Figure 7 and 8 . The FIS output clearly shows that the proposed method can be effectively used for diagnosing incipient faults of power transformers.

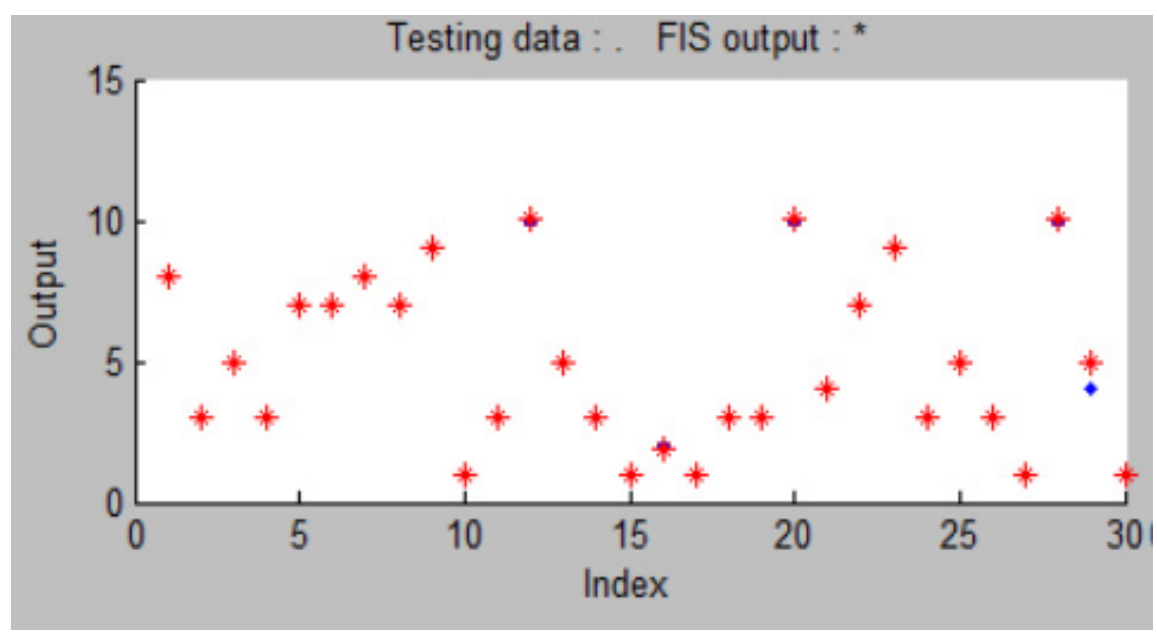

Figure 7. Testing output for Rogers Ratio Method-Based ANFIS

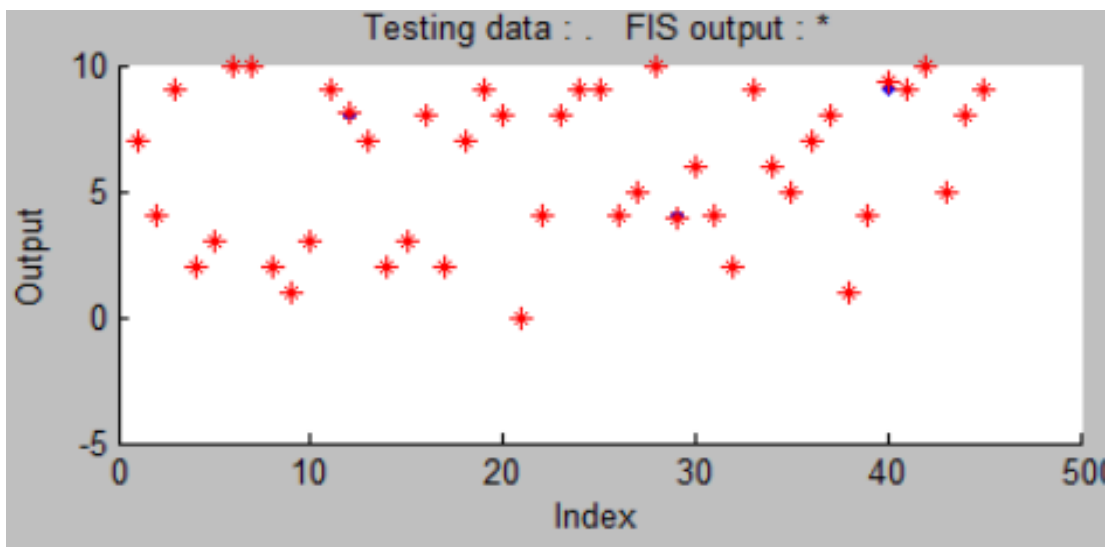

Figure 8. Testing the output of IEC Ratio Method-Based ANFIS

\section{Results and Discussion}

Sampling of power transformer oils was performed at the sites where these transformers are located for more than 15 years. The 30 samples used for the detection of the DGA in oil and the results of the analysis, are presented in Table 5. Insertion of the data ratios of gas-derived samples from Table 5 to the expert system 
interface was tested in each case. The results, as summarized in Table 6, are good and in agreement with the specifications of approved standards for diagnosing faults and assessing quality of insulating oils. The results obtained through the ANFIS Expert System suggest that identifying the status of transformer oil while in service is an important and necessary maintenance step to ensure long-term functioning of the transformer oil. The results of the test, as presented in Table 6, are satisfactory. Results observed prior to identifying faults are accurate statements of the type of fault and the assessment of the quality of the oil, which are guides in providing treatment. In some cases, faults that could not be diagnosed by the Rogers ratio method were diagnosed successfully using the IEC ratio method, and vice versa.

Table 5. Value of gases in ppm data input to ANFIS expert system

\begin{tabular}{cccccc}
\hline NO. & $\mathrm{CH}_{4}$ & $\mathrm{H}_{2}$ & $\mathrm{C}_{2} \mathrm{H}_{6}$ & $\mathrm{C}_{2} \mathrm{H}_{4}$ & $\mathrm{C}_{2} \mathrm{H}_{2}$ \\
\hline 1 & 47 & 191 & 43 & 15 & 0.0001 \\
2 & 200 & 50 & 300 & 200 & 50 \\
3 & 245 & 36 & 144 & 332 & 0.0001 \\
4 & 187 & 86 & 136 & 363 & 0.0001 \\
5 & 24 & 10 & 372 & 24 & 0.0001 \\
6 & 7 & 17 & 13 & 3 & 0 \\
7 & 42 & 206 & 16 & 82 & 221 \\
8 & 999 & 769 & 234 & 1599 & 31 \\
9 & 50 & 1000 & 40 & 30 & 10 \\
10 & 107 & 127 & 11 & 154 & 224 \\
11 & 9739 & 2004 & 2750 & 5114 & 0 \\
12 & 144 & 60 & 67 & 449 & 9 \\
13 & 3 & 4 & 2 & 1 & 0 \\
14 & 53 & 65 & 41 & 95 & 14 \\
15 & 79 & 33 & 30 & 215 & 5 \\
16 & 370 & 1249 & 56 & 606 & 1371 \\
17 & 1053 & 507 & 297 & 1440 & 17 \\
18 & 77 & 57 & 19 & 21 & 0 \\
19 & 10 & 160 & 3 & 1 & 1 \\
20 & 770 & 199 & 217 & 1508 & 72 \\
21 & 695 & 416 & 74 & 867 & 0 \\
22 & 27 & 10 & 49 & 4 & 1 \\
23 & 940 & 1450 & 211 & 322 & 61 \\
24 & 1.7 & 2.35 & 0.6 & 1.2 & 0.1 \\
25 & 96 & 240 & 20 & 8 & 5 \\
26 & 4000 & 960 & 1290 & 1560 & 6 \\
27 & 73 & 980 & 58 & 12 & 0 \\
28 & 1500 & 280 & 1200 & 150 & 40 \\
29 & 8517 & 2844 & 10196 & 4422 & 39 \\
30 & 4 & 8 & 350 & 24 & 2 \\
\hline & & & & &
\end{tabular}

Table 6. Results of diagnosing faults and assessng the quality of insulating oil

\begin{tabular}{|c|c|c|c|}
\hline \multirow{2}{*}{ NO. } & \multicolumn{2}{|c|}{ Fault Type } & \multirow{2}{*}{$\begin{array}{l}\text { Oil } \\
\text { Treatment }\end{array}$} \\
\hline & Rogers Ratio & IEC Ratio & \\
\hline 1 & Normal deterioration & No Fault & $\begin{array}{l}\text { Single filtering \& } \\
\text { degassing }\end{array}$ \\
\hline 2 & Overheating $-150-200{ }^{\circ} \mathrm{C}$ & Unidentifiable & $\begin{array}{l}\text { Single filtering \& } \\
\text { degassing }\end{array}$ \\
\hline 3 & Unidentifiable & $\begin{array}{l}\text { Thermal fault of medium } \\
\text { Temperature } 300-700^{\circ} \mathrm{C}\end{array}$ & $\begin{array}{l}\text { Double filtering \& } \\
\text { degassing }\end{array}$ \\
\hline 4 & Winding Circulating Currents & $\begin{array}{l}\text { Thermal fault of medium } \\
\text { Temperature } 300-700^{\circ} \mathrm{C}\end{array}$ & $\begin{array}{l}\text { Double filtering \& } \\
\text { degassing }\end{array}$ \\
\hline 5 & Overheating $-150-200^{\circ} \mathrm{C}$ & Thermal fault of low temperature - & Single filtering \& \\
\hline
\end{tabular}




\begin{tabular}{|c|c|c|c|}
\hline & & $150-300{ }^{\circ} \mathrm{C}$ & degassing \\
\hline 6 & Overheating $-200-300^{\circ} \mathrm{C}$ & No Fault & Good Oil \\
\hline 7 & Arc with Power Follow-Through & Discharges of High Energy & $\begin{array}{l}\text { Double filtering \& } \\
\text { degassing }\end{array}$ \\
\hline 8 & Core and Tank Circulating Currents & $\begin{array}{l}\text { Thermal fault of High Temperature - } \\
\text { above } 700^{\circ} \mathrm{C}\end{array}$ & Reclamation \\
\hline 9 & Partial discharge & $\begin{array}{l}\text { Partial Discharges of High Energy } \\
\text { Density }\end{array}$ & $\begin{array}{l}\text { Double filtering \& } \\
\text { degassing }\end{array}$ \\
\hline 10 & Arc with Power Follow-Through & Discharges of High Energy & $\begin{array}{l}\text { Double filtering \& } \\
\text { degassing }\end{array}$ \\
\hline 11 & Unidentifiable & $\begin{array}{l}\text { Thermal fault of medium } \\
\text { Temperature } 300-700{ }^{\circ} \mathrm{C}\end{array}$ & Do Not use \\
\hline 12 & Core and Tank Circulating Currents & $\begin{array}{l}\text { Thermal fault of High Temperature - } \\
\text { above } 700{ }^{\circ} \mathrm{C}\end{array}$ & $\begin{array}{l}\text { Double filtering \& } \\
\text { degassing }\end{array}$ \\
\hline 13 & $\begin{array}{l}\text { Flashover without Power Follow- } \\
\text { Through }\end{array}$ & Unidentifiable & Good Oil \\
\hline 14 & General Conductor Overheating & Discharges of Low Energy & $\begin{array}{l}\text { Single filtering \& } \\
\text { degassing }\end{array}$ \\
\hline 15 & Core and Tank Circulating Currents & $\begin{array}{l}\text { Thermal fault of High Temperature - } \\
\text { above } 700^{\circ} \mathrm{C}\end{array}$ & $\begin{array}{l}\text { Single filtering \& } \\
\text { degassing }\end{array}$ \\
\hline 16 & Arc with Power Follow-Through & Discharges of High Energy & Reclamation \\
\hline 17 & Core and Tank Circulating Currents & $\begin{array}{l}\text { Thermal fault of High Temperature - } \\
\text { above } 700^{\circ} \mathrm{C}\end{array}$ & Reclamation \\
\hline 18 & Winding Circulating Currents & $\begin{array}{l}\text { Thermal fault of medium } \\
\text { Temperature } 300-700^{\circ} \mathrm{C}\end{array}$ & $\begin{array}{l}\text { Single filtering \& } \\
\text { degassing }\end{array}$ \\
\hline 19 & Partial Discharge with Tracking & $\begin{array}{l}\text { Partial Discharges of High Energy } \\
\text { Density }\end{array}$ & $\begin{array}{l}\text { Single filtering \& } \\
\text { degassing }\end{array}$ \\
\hline 20 & Unidentifiable & $\begin{array}{l}\text { Thermal fault of High Temperature - } \\
\text { above } 700^{\circ} \mathrm{C}\end{array}$ & Reclamation \\
\hline 21 & $\begin{array}{l}\text { Core and Tank Circulating Currents, } \\
\text { overheated joints }\end{array}$ & $\begin{array}{l}\text { Thermal fault of High Temperature - } \\
\text { above } 700^{\circ} \mathrm{C}\end{array}$ & $\begin{array}{l}\text { Double filtering \& } \\
\text { degassing }\end{array}$ \\
\hline 22 & Overheating $-150-200^{\circ} \mathrm{C}$ & Unidentifiable & Good Oil \\
\hline 23 & General Conductor Overheating & Discharges of Low Energy & Reclamation \\
\hline 24 & General Conductor Overheating & $\begin{array}{l}\text { Thermal fault of low temperature - } \\
\text { below } 150^{\circ} \mathrm{C}\end{array}$ & Good Oil \\
\hline 25 & $\begin{array}{l}\text { Flashover without Power Follow } \\
\text {-Through }\end{array}$ & Unidentifiable & $\begin{array}{l}\text { Single filtering \& } \\
\text { degassing }\end{array}$ \\
\hline 26 & Unidentifiable & $\begin{array}{l}\text { Thermal fault of medium } \\
\text { Temperature } 300-700^{\circ} \mathrm{C}\end{array}$ & Do Not use \\
\hline 27 & Partial discharge & $\begin{array}{l}\text { Partial Discharges of Low Energy } \\
\text { Density }\end{array}$ & $\begin{array}{l}\text { Double filtering \& } \\
\text { degassing }\end{array}$ \\
\hline 28 & Slight Overheating - below $150^{\circ} \mathrm{C}$ & Unidentifiable & Reclamation \\
\hline 29 & Overheating $-150-200^{\circ} \mathrm{C}$ & $\begin{array}{l}\text { Thermal fault of low temperature - } \\
150-300{ }^{\circ} \mathrm{C}\end{array}$ & Do Not use \\
\hline 30 & Unidentifiable & No Fault & $\begin{array}{l}\text { Single filtering } \\
\text { \&degassing }\end{array}$ \\
\hline
\end{tabular}

\section{Conclusion}

We introduced a simple but accurate ANFIS Expert System to identify the type of fault and to assess the quality of insulating oil in power transformers. The DGA in oil, being the reliable method, was used for fault diagnosis and insulation oil quality evaluation. The Rogers ratio and the IEC ratio methods using DGA in oil were used where the software employed ANFIS through the MATLAB program. The expert system was found reliable for diagnosing faults and assessing the quality of insulating oil. The results are satisfactory based on their adherence to the specifications of the IEEE standard C57-104 and the IEC standard 60599. Thus, the software results can 
be used by maintenance teams to rectify the occurrence of sudden faults that result in power disruption and economic loss. The nature of faults was accurately and efficiently detected and the oil replacement was determined as the output.

\section{References}

Anon. The J \& P Transformer Book J \& P Books.

Committee, T., Power, I., \& Society, E. (2009). IEEE Std C57.104'-2008 (Revision of IEEE Std C57.104-1991). IEEE Guide for the Interpretation of Gases Generated in Oil-Immersed Transformers.

Foong, K. C., Chee, C. T., \& Wei, L. S. (2009). Adaptive network fuzzy inference system (ANFIS) handoff algorithm. International Conference on Future Computer and Communication, ICFCC, 1(2), 195-198.

Gao, N., Zhang, G. J., Qian, Z., Yan, Z., \& Zhu, D. H. (1998). Diagnosis of DGA based on fuzzy and ANN methods. Proceedings of 1998 International Symposium on Electrical Insulating Materials. 1998 Asian International Conference on Dielectrics and Electrical Insulation. 30th Symposium on Electrical Insulating Ma.

Muhamad, N. A. et al. (2007). Comparative Study and Analysis of DGA Methods for Transformer Mineral Oil. 2007 IEEE Lausanne Power Tech, 45-50. Retrieved from http://ieeexplore.ieee.org/lpdocs/epic03/wrapper.htm?arnumber=4538290

Nunes, D. S. I., Imamura, M. M., \& Souza, A. N. D. (2000). The application of neural networks to the analysis of dissolved gases in insulating oil used in transformers. Smc 2000 conference proceedings. 2000 IEEE International Conference on systems, man and cybernetics. Cybernetics evolving to systems, humans, organizations, and their complex interactions, 4, 2643-2648.

Rogers, R. R. (1978). IEEE and IEC Codes to Interpret Incipient Faults in Transformers, Using Gas in Oil Analysis. IEEE Transactions on Electrical Insulation, 13(5), 349-354.

Sarma, D. V. S. S. S., \& Kalyani, G. N. S. (2004). Ann approach for condition monitoring of power transformers using DGA. IEEE Region 10 Conference TENCON 2004, 444-447. Retrieved from http://ieeexplore.ieee.org/lpdocs/epic03/wrapper.htm?arnumber=1414803

Satyanarayana, K. V. et al. (2008). Application of Artificial Intelligence for the Assessment of the Status of Power Transformers, 104-107.

Shirkhodaie, A., Muthuswamy, S. K., \& Saravanan, S. S. (1998). A Hybrid Neuro-Fuzzy Based Fault Diagnostic. Technique for Bearings Condition-Based Maintenance, 724.

Sun, X., Sun, X., Liang, Y., Lv, D., Liu, D., \& Bian, J. (2010). Application of Kernel C-means clustering and Dempster-Shafer theory of evidence in power transformers fault diagnosis. Proceedings - 2010 7th International Conference on Fuzzy Systems and Knowledge Discovery, 3, 1060-1063.

\section{Copyrights}

Copyright for this article is retained by the author(s), with first publication rights granted to the journal.

This is an open-access article distributed under the terms and conditions of the Creative Commons Attribution license (http://creativecommons.org/licenses/by/3.0/). 